Philologica Canariensia 23 (2017), pp. 49-62 eISSN: 2386-8635

DOI: 10.20420/PhilCan.2017.148

Recibido: 2 de noviembre de 2016; versión revisada aceptada: 10 de enero de 2017

Publicado: 26 de junio de 2017

\title{
EL HIPERVERSÍCULO EN LA GENERACIÓN DE LOS NOVÍSIMOS
}

\author{
Miguel ÁNGEL MÁRQUEZ GUERRERO \\ Universidad de Huelva
}

\begin{abstract}
RESUMEN: Este artículo estudia una unidad métrica mayor que el versículo del verso libre, a la que denomino "hiperversículo". El verso libre innova la silva modernista introduciendo el versículo, verso compuesto de miembros que comparten el ritmo endecasilábico de los versos simples. La prosificación de los poemas en la última etapa de Juan Ramón Jiménez quedó como un desarrollo extremo y marginal. Sin embargo, el hiperversículo de los novísimos aparece en los sesenta como un puente entre el verso libre inicial y sus formas 'prosificadas'. Por otra parte, el hiperversículo es un rasgo de la poética de los novísimos que los vincula a las vanguardias.
\end{abstract}

PALABRAS CLAVE: teoría literaria, métrica, verso libre, hiperversículo, novísimos

\section{The hyperverse in the "novísimos" generation}

ABSTRACT: This article examines the "hyperverse", as I will call the metric unit longer than the typical free verse line. The free verse innovates the modernist silva by introducing the versículo, a compound line whose members share the general hendecasyllabic rhythm. The prosification of Juan Ramón Jiménez's last poems meant a radical evolution of the free verse, but this move remained marginal. However, the hyperverse of the "novísimos" arises in the sixties as a link between the original free verse and its prosified variety. Besides, the hyperverse is a characterizing feature of the poetry of the "novísimos" which relates their generation to the vanguard.

KEYWORDS: literary theory, metrics, free verse, hyperverse, novísimos

\section{NOVÍSIMOS Y POETAE NOVI}

Como apuntó Jaime Siles (1988), la antología Nueve novísimos poetas españoles de J. M. Castellet (1970) es el correlato hispánico de una antología italiana anterior, I Novissimi. Poesie per gli anni '6o publicada por Alfredo Giulani (1961). ${ }^{1}$ Pero más allá de lo que parece ser un préstamo indudable del adjetivo 'novísimos', cabe señalar una relación mucho más antigua y profunda de los poetas novísimos españoles con los poetae noui romanos. ${ }^{2}$ En este mismo sentido, Túa Blesa $(1995,19)$ vinculó la poesía de Leopoldo María Panero con Catulo, el principal representante de los poetae noui, y los poetas epigramáticos griegos: "1982 es el año de Dióscuros, conjunto de poemas inspirados en la Antología palatina y en Catulo, una de sus lecturas de siempre [de Leopoldo María Panero], donde da su tratamiento particular de una de las vetas de lo que fue la mina novísima, la antigüedad greco-latina”. 
Como los novísimos, los poetae noui romanos formaban un grupo generacional. Muchos de ellos procedían de la Galia Transpadana (Catulo nació en Verona), y están más unidos por el rechazo de la poesía anterior que por propósitos estéticos comunes. La 'poesía nueva' es, de hecho, la recusación de la antigua poesía romana, en su forma y en su contenido. Los poetae noui romanos pretenden seguir a sus modelos alejandrinos para incorporar la poesía romana a la tradición helénica:

Es l'art pour l'art: en parte es el tratamiento de motivos remotos, llevado a cabo con una selecta erudición, que exige la intervención del comentarista (se desea ser un poeta doctus) y, en parte, la elaboración atildada aun de las vivencias personales más insignificantes; y ambas cosas con la idea de ejecutar el más excelso arte formal [...] el favor del que gozan los términos y formas verbales del griego se debe a su sonido [...] se afina el oído para la melodía lingüística y métrica y se valoriza la esmerada selección de las palabras y su artística colocación (Bieler, 1982, 165-166).

Naturalmente, la crítica más conservadora acusó a los poetae noui de imitadores serviles de los alejandrinos. Del mismo modo, los novísimos rechazaban la poesía española inmediatamente anterior; seguían modelos poéticos foráneos (Eliot, Pound, etc.) en su intento de incorporar la poesía española a la corriente cultural europea y americana del siglo XX. Así pues, nuestros novísimos, sean o no sean conscientes, encuentran sus predecesores más antiguos en los poetae noui romanos del siglo I a. C., incluso en su aprecio de la poesía alejandrina, como señaló Jaime Siles (2006, 276-277), quien cita una declaración explícita en ese sentido de Luis Antonio de Villena.

\section{FINAL DEL TÚNEL}

El afán de arrebatar a los poetas novísimos (me refiero ahora a los poetas novísimos españoles) el mérito de haber salido de un largo túnel lleva a enunciar que muchos poetas maduros de la generación anterior (como Gil de Biedma), e incluso de la anterior a la anterior (como José Hierro), habían iniciado ya la superación de la poesía realista y social. La discusión en esos términos carece de sentido porque, entre los años 1965 y 1966, Vicente Aleixandre escribió los Poemas de la consumación (1968); sobre la técnica irracionalista de ese poemario, nos dice el propio Aleixandre (1977, 307):

En este libro sentí la precisión del empleo en mi verso de los elementos irracionales, pero sin que esto supusiese un innecesario retorno a las formas expresivas ya usadas en mi etapa superrealista. Traté, pues, de irracionalizar el elemento expresivo 'desde' la experiencia del realismo, si se me permite la inexacta palabra, [...] con lo cual se evitaba simultáneamente la repetición de la zona expresiva inmediatamente anterior y de la etapa superrealista, más anterior aún.

Así pues, al margen de reivindicaciones individuales, fue la propia dinámica estética la que hizo que los poetas más innovadores de las diferentes generaciones que coexistían (Aleixandre, Hierro, Gil de Biedma, Gimferrer) se apartaran de los caminos trillados que había seguido la poesía española en las dos décadas anteriores (Siles, 2006). 


\section{VERSO LIBRE Y VERSÍCULO}

Es evidente que, por una parte, los novísimos entroncan con las poéticas vanguardistas y que, por otra, intentan superar los estrechos límites de la autarquía franquista buscando horizontes culturales más lejanos. Esta tesis se ha fundamentado en múltiples aspectos tanto formales como de contenido. Por ejemplo, la técnica irracionalista ya aludida por Aleixandre y visible en el primer Gimferrer, o el uso extenso e intenso de la mitología clásica (Cristóbal, 2000). Sin embargo, es el verso libre la herencia más clara que recibieron los novísimos de la poesía de Juan Ramón Jiménez, Aleixandre o Cernuda. Este rasgo generacional resulta más patente si lo comparamos con la vuelta a la versificación tradicional de algunos movimientos posteriores a los novísimos, y cito a García Posada $(1996,19)$ para resaltar el contraste:

El versolibrismo caracterizó en general a los poetas novísimos. Veinte años más tarde la situación se ha invertido. El retorno al verso medido y a las formas métricas tradicionales resulta muy notorio. [...]. Curiosamente, el versolibrismo es hoy un fenómeno sobre todo femenino, como puede comprobarse en las antologías ad hoc.

Estas palabras, en las que bajo la crítica literaria se adivina cierto regusto misógino, pueden servirnos para comprender hasta qué punto son importantes tanto la versificación que una generación poética selecciona, como las innovaciones que introduce en la misma. Los novísimos adoptaron el verso libre de ritmo endecasilábico 3 que introdujeron en la poesía española Unamuno y Juan Ramón Jiménez, y que más tarde fue desarrollado por poetas como Aleixandre, García Lorca o Cernuda.

Se trata de un tipo de verso libre que evolucionó a partir de la silva modernista. ${ }^{4} \mathrm{Su}$ innovación más importante es un verso compuesto cuyos miembros responden al ritmo endecasilábico general. Se ha denominado "versículo" a este verso (Márquez, 2000).5 En la poesía escrita en verso libre de Juan Ramón Jiménez, junto a los versos de 5, 7, 9 y 11 sílabas, hallamos alejandrinos (7+7), y otros versos compuestos generalmente de dos miembros de ritmo endecasilábico, es decir, con 5, 7, 9 u 11 sílabas. Veamos, como ejemplo, el principio de Espacio en su inicial versión en verso:

$\begin{array}{lr}\text { Los dioses no tuvieron más sustancia } & {[11]} \\ \text { que la que tengo yo. Yo tengo, como ellos, } & {[7+7]} \\ \text { la sustancia de todo lo vivido } & {[11]} \\ \text { y de todo lo porvivir. No soy presente sólo, } & {[9+7]} \\ \text { sino fuga raudal de cabo a fin. Y lo que veo } & {[11+5]} \\ \text { a un lado y otro, en esta fuga, } & {[9]} \\ \text { rosas, restos de alas, sombra y luz } & {[11]} \\ \text { es sólo mío, } & {[5]} \\ \text { recuerdo y ansia míos, presentimiento, olvido. } & {[7+7]}\end{array}$

Los versículos con tres miembros son muy raros en la poesía de Juan Ramón Jiménez (Unamuno de hecho no los utilizó nunca), aunque pueden señalarse algunos casos, como en "Víspera" de Diario de un poeta recién casado: 
Decimos: iYa está todo!

Y los ojos se vuelven, tristemente,

buscando no sé qué, que no está con nosotros,

algo que no hemos visto

y que no ha sido nuestro,

ipero que es nuestro porque pudo serlo...! iAdiós!

iAdiós! iAdiós! iAdiós a todas partes, aun sin irnos

y sin querernos ir y casi yéndonos!
[7]

[11]

$[7+7]$

[7]

[7]

$[11+7+11]$

[11]

Los poetas del 27 desarrollaron esta tendencia y con frecuencia sus versículos se alargan en más de dos miembros; véase el inicio de "Sin luz" de Vicente Aleixandre (La destrucción o el amor, 1932-1933):

El pez espada, cuyo cansancio se atribuye ante todo
a la imposibilidad de horadar a la sombra,
$\begin{aligned} & \text { de sentir en su carne la frialdad del fondo de los } \\ & \text { mares donde el negror no ama, }\end{aligned}$
donde faltan aquellas frescas algas amarillas
que el sol dora en las primeras aguas.

La clave del verso libre de ritmo endecasilábico se halla en el versículo, que cumple una doble función rítmica. Por un lado, innova la tradición porque no parte de un metro fijo ni el receptor conoce ese metro de antemano. Pero, por otro lado, su base rítmica (la serie acentual del endecasílabo) es la tradicional de la poesía culta española y puede ser reconocida por el oído del receptor a pesar de la apariencia nueva y extraña. El versículo consigue renovar la métrica tradicional y permite, al mismo tiempo, que el receptor se adapte al nuevo sistema inconscientemente (Márquez, 2000). Además de esta función rítmica, el versículo ofrece variaciones estilísticas, pues enlentece el tiempo del poema con su tono más grave que el de los versos simples. Por último, el versículo es para el poeta un vehículo mayor que los versos simples, en el que explayar la materia literaria con unos límites menos constreñidos, y en el que la ruptura de los grupos fónicos por las cesuras está atenuada con respecto a los encabalgamientos.

\section{HIPERVERSÍCULO}

En el período de postguerra, el verso libre de ritmo endecasilábico fue definiendo su naturaleza (por ejemplo, disminuyen las irregularidades), y se convirtió en la forma poética habitual de los mejores poetas de la generación del 27 que habían sobrevivido a la guerra civil. ${ }^{6}$ Sin solución de continuidad, este verso llega hasta la década del 60; los primeros poemarios de Pere Gimferrer son rupturistas en muchos aspectos y también en lo que respecta al verso libre. Desde las composiciones iniciales de La muerte en Beverly Hills (1967), el verso libre de ritmo endecasilábico se acompaña de largos versículos de tres e incluso cuatro miembros; véase La muerte en Beverly Hills I: 
Mimbre, bebidas de colores vivos, luces oxigenadas que chorrean despacio.

$[11+7+7]$

Bañando en un oscuro esplendor las espaldas, acariciando con fulgor de hierro blanco,

Unos hombros desnudos, unos ojos eléctricos, la dorada caída de una mano en el aire sigiloso,

$[7+7+9+5]$

$[7+7+7+11]$

Estos larguísimos versos culminan la evolución que parte de los dodecasílabos de Unamuno y Juan Ramón Jiménez (7+5 o 5+7), y de otros versos compuestos mayores como 5+9, etc. Sin embargo, en La muerte en Beverly Hills, hallamos además unidades métricas que parecen superar los límites de lo que habitualmente se denomina versículo; véase La muerte en Beverly Hills VII:

A punto de morir, como las luces de un avión en la noche, [11+7] Cuerpo tibio o cristales empañados en la dulce penumbra [11+7]

Cómo besa despacio una llave de plata tus espaldas que tiemblan, [7+7+7]

Con un pulso de orquídeas y ascensores ardiendo. [7+7]

Vienen y van, de la azul lejanía plateada, los albatros, los globos cautivos, los grandes expresos, con destellar de música y rieles.

Una luz de relámpagos, tan suave como la sangre de un delfín herido, secuestrada en el viento helado las palabras de amor. Opaca noche en los escaparates.

El mar en sus cavernas como el alba en sus túneles. ¿De dónde vienes, dime, rostro herido, bailarina del pañuelo ensangrentado, amor mío de entonces, más que yo mismo entonces, por quien quise morir y tuve frío como un vidrio quebrado en la noche?

Analicemos estos tres últimos versos mayores, que superan ampliamente los límites de los versículos habituales, con tres o cuatro miembros:

Vienen y van,

de la azul lejanía plateada,

los albatros, los globos

cautivos, los grandes expresos,

Una luz de relámpagos, tan suave

Opaca noche en los escaparates.

El mar en sus cavernas 
¿De dónde vienes, dime, rostro herido, bailarina del pañuelo

ensangrentado, amor mío de entonces, más que yo mismo entonces, por quien quise morir y tuve frío como un vidrio quebrado en la noche?
[11]

[9]

[11]

[7]

[11]

[7]

[4]

El procedimiento técnico empleado es el mismo, pero su composición de hasta nueve miembros nos permite proponer una entidad nueva, intermedia entre el versículo y la prosa de ritmo endecasilábico que Juan Ramón Jiménez emprendió en Espacio y los otros poemas de su etapa americana ( $\S 5$ ). Podríamos denominar a esta innovación métrica 'hiperversículo'.

Debemos preguntarnos si esos hiperversículos de Gimferrer son rítmicamente idénticos al conjunto de versos simples que se originarían de su descomposición. Si fueran idénticos, negaríamos toda esencia al versículo y al hiperversículo, que serían un recurso visual más que una innovación rítmica. Pero, como ha señalado Domínguez Caparrós (1988a, 23), la representación gráfica no es arbitraria sino que manifiesta la intención rítmica del autor. La eliminación de los finales de verso parece ser el objetivo rítmico de la aglutinación de versos simples en versículos e hiperversículos. Pero ċse trata de una eliminación total de los finales de verso o, más bien, de la sustitución por otro elemento rítmico? En realidad, la pausa de final de verso se sustituye por la pausa de final de hemistiquio. Las dos pausas parecen cumplir el mismo papel métrico (impedir las sinalefas, igualar finales agudos, llanos y esdrújulos, etc.); sin embargo, un nuevo concepto métrico - el tiempo del poema- permite la distinción de esas dos pausas: la pausa de final de verso es una marca pertinente para el tiempo del poema. La pausa de final del hemistiquio, por el contrario, no lo es. Un ejemplo, un poema escrito en alejandrinos posee un tiempo más lento que un poema escrito en heptasílabos (Márquez, 2000).

\section{PROSA ENDECASILÁBicA}

La lógica interna, la dinámica evolutiva natural parece llevar a que el verso libre, explayado en versículos e hiperversículos, se presente como prosa. Es de sobra conocido que Juan Ramón Jiménez, hacia el final de la década del 40, comenzó a presentar como prosa toda su poesía escrita en verso libre, comenzando por el poema Espacio (Márquez, 2003). El fenómeno presenta un parentesco con la aglutinación de versos simples en versos compuestos. Martínez Fernández (1996, 58-59) señaló que, en la literatura contemporánea, la serie en prosa disfraza gráficamente el endecasílabo o cualquier otro metro (cita ejemplos de Ullán, Caballero Bonald y Umbral). Igualmente mostró que al menos algunos "poemas en bloques" de Antonio Gamoneda se basan en el ritmo endecasilábico.7 En este sentido, aduce varias composiciones integradas en Lápidas (1986), como la siguiente:

Dime quién eres antes de acercarte más a mi corazón, tu nombre en la ciudad que existe detrás de ti, 
la que fue joven en tus ojos y aún recuerdas antes de entrar en los ambulatorios donde la patria habla a tus sobrinas parturientas.

Dime quién eres entre los grandes brazos de Jesucristo, en la chaqueta de las madres, en la dulzura de los hombres cansados

Martínez Fernández analiza el primer "bloque" de esa composición, que se basa en el ritmo endecasilábico $(1996,78)$ :

Dime quién eres antes de acercarte

Más a mi corazón

Tu nombre en la ciudad que existe

Detrás de ti,

La sangría francesa nos indica que se trataría de un simple versículo con cuatro miembros. También el segundo bloque sería un versículo, aunque ahora de cinco miembros:

la que fue joven en tus ojos

y aún recuerdas antes de entrar

en los ambulatorios

donde la patria habla

a tus sobrinas parturientas
[9]

[9]

[7]

[7]

[9]

Sin embargo, Martínez Fernández cita otros "bloques" que se presentan como pura prosa. Por ejemplo, el siguiente:

CONVOCADA por las mujeres, la madrugada cunde como ramos frescos: cuñadas fértiles, madres marcadas por la persecución. Hay un friso de ortigas en el perfil de la mañana; lienzos retorcidos en exceso por manos encendidas en la lejía y la desesperación.

También este responde al ritmo endecasilábico, a pesar de que carece de sangría francesa o de cualquier otro medio tipográfico que marque el bloque como una línea versal. El análisis por miembros sería el siguiente:

CONVOCADA por las mujeres

La madrugada cunde como ramos

frescos: cuñadas fértiles,

madres marcadas

por la persecución.

Hay un friso de ortigas

[7]

en el perfil de la mañana; 
lienzos retorcidos

en exceso por manos encendidas

en la lejía y

$\left[\begin{array}{lll}7 & 0 & 5\end{array}\right]^{8}$

la desesperación.

[7]

Así, pues, no debería olvidarse que el verso libre, con sus versículos e hiperversículos, es el punto de partida de esta prosa endecasilábica. El experimento juanramoniano de presentar como prosa las composiciones endecasilábicas fue continuado por algunos poetas de la generación de los novísimos desde sus primeras obras. Así, Jaime Siles en Génesis de la luz (1969) incluyó entre otros el siguiente poema titulado "Edgar Allan Poe":

En la ventana apareció de pronto, prendido de una tela de araña, un ojo frío. Ojo de virgen ahogada por el viento. Ojo de nieve. Polar palpitación de las gaviotas.

El análisis a partir del ritmo endecasilábico resulta patente:

En la ventana apareció de pronto,

prendido de una tela

de araña, un ojo frío.

[7]

Ojo de virgen

[5]

ahogada por el viento.

[7]

Ojo de nieve.

[5]

Polar palpitación de las gaviotas.

[11]

El recurso se repite en otras composiciones del mismo poemario, como la titulada "No":

iNo! iNo! No es esa luz dormida de los astros bajo la tierra muerta. Ni el anhelante grito del corazón ahogado. Ni el aire terso que los dientes horadan.

Tal vez la cabellera de una muchacha hundida bajo el mar sin memoria. Acaso ese latido de agua que se incendia, ese líquido trueno de tormentas y manos, de uñas insensibles que tu pecho soporta.

Toda la vacuidad de la esperanza cabe en los exactos límites de un rostro nunca visto.

Sólo el liquen resiste el dolor de las sombras: la dureza imprevista con que la lluvia muerde los relojes.

Los ecos alexandrinos son evidentes no solo en la imaginería de raíz surrealista sino también en el predominante ritmo heptasilábico (o alejandrino, si se prefiere):

No! iNo! No es esa luz dormida de los astros bajo la tierra muerta. 
Ni el anhelante grito

del corazón ahogado.

$\mathrm{Ni}$ el aire terso

que los dientes horadan.

Etc.

Todos los miembros son heptasílabos, salvo un pentasílabo ("No el aire terso") y el endecasílabo final ("con que la lluvia muerde los relojes”). La división del poema en párrafos apunta hacia una similitud de estos párrafos con los hiperversículos. Algo similar observamos en el primer poema de Canon (1969-1973):

Mis labios llegan a la playa más alta, a la arena más honda, a besar esos átomos, sin espacio, del aire. Beben la espuma herida por cuerpos temblorosos, acarician las noches de estaño o laterita, modulan tibiamente el perfil de las voces, las palabras sin rostro de las luces oscuras.

Hay un túnel de sombra más allá de los ojos. Y un hilo verde dice que la memoria existe. Es la retina viva que vibra en la garganta, el oleaje eterno que desconoce límites, el caballo sin freno que la muerte detiene.

Este poema está compuesto por miembros heptasilábicos, salvo el primero, que es un pentasílabo ("Mis labios llegan"). De nuevo la división en dos párrafos apunta a dos largos hiperversículos.

Este tipo de composición poética tuvo una continuación sorprendente y muy interesante en Purgatorio (1986) de Jenaro Talens. Escrito en catalán por un castellanohablante de Tarifa (1946), fue traducido al castellano por Antonia Cabanilles. El libro aparece como prosa, salvo la primera composición, que se presenta en verso libre, quizá con la intención de que el lector sea consciente de que está leyendo un libro de poesía. Leamos el poema titulado "Voi ch'entrate" en ambas lenguas, un solo ejemplo de lo que es la norma de este poemario:

Els que estimen la nit, mai no estimen una nit com aquesta. Ací tothom s'embosca sota remor d'escumes, reconoixent en la buidor del cos la cambra fugitiva. Pedres de cel, llençades com silenci, es borren el visible amb un fum de paraules. La vida, qui la viu? La sang ja no és el centre, tan sols sorgeix un cor de boira, tota llum innombrable.

Quienes aman la noche, nunca han amado noches como ésta. Aquí todo está oculto bajo rumor de espumas, y la oquedad del cuerpo se reconoce espacio fugitivo. Piedras de cielo, que el silencio arroja, disuelven lo visible en humo de palabras. La vida, ¿quién la vive? La sangre ya no es centro; tan sólo surge un corazón de niebla, toda luz innombrable. 
El análisis deja clara la base rítmica de esta composición aparentemente en prosa:9

Els que estimen la nit, mai no estimen una nit com aquesta.

Ací tothom s'embosca sota remor d'escumes, reconoixent en la buidor del cos la cambra fugitiva.

Pedres de cel, llençades com silenci, es borren el visible amb un fum de paraules. La vida, qui la viu? La sang ja no és el centre, tan sols sorgeix un cor de boira, total llum innombrable.

Quienes aman la noche, nunca han amado noches como ésta. Aquí todo está oculto bajo rumor de espumas, y la oquedad del cuerpo se reconoce espacio fugitivo.

Piedras de cielo, que el silencio arroja, disuelven lo visible en humo de palabras. La vida, ¿quién la vive? La sangre ya no es centro; tan sólo surge un corazón de niebla, toda luz innombrable.
[6]

[10]

$[6+6]$

[10]

La traducción es excelente, desde todos los puntos de vista, y también desde el punto de vista métrico. Las únicas diferencias entre ambas versiones son la inversión de heptasílabo y endecasílabo en las líneas 4 y 5, y la sustitución de un eneasílabo por un endecasílabo en la penúltima línea. Creo que la coincidencia de ambas versiones garantiza el análisis propuesto.

La presentación como prosa de una composición escrita sobre la base rítmica endecasilábica es un hecho que puede rastrearse en diversos momentos de la poesía española del siglo XX. Ahora bien, José Antonio Moreno Jurado (Sevilla, 1946), autor estrictamente coétaneo a los novísimos, nos proporciona una ligera modificación del fenómeno. Su poemario Mitología personal (1985) alterna composiciones en verso y composiciones en prosa con una marca tipográfica - un asterisco- a lo largo del "párrafo"; véase "Deucalión” I:

Quizás tu voz * como vino de Odín escanciado en los bosques de septiembre * como fuego entre zarzas que nunca se consumen * o mil brazos en un torso dulcísimo de Oriente * dentro de mí tu voz como almuhédanos al grito.

Cuyo análisis es:

Quizás tu voz

como vino de Odín escanciado en los bosques de septiembre $\quad[7+11]$ como fuego entre zarzas que nunca se consumen $\quad[7+7]$

o mil brazos en un torso dulcísimo de Oriente [4+11]

dentro de mí tu voz como almuhédanos al grito. [7+9] 
Los asteriscos corresponden de manera patente a los finales de verso en una composición escrita en verso libre de ritmo endecasilábico con predominio de versículos. Por el contrario, lo que serían finales de hemistiquios no reciben ninguna marca.

\section{REANUDAR LA POESÍA}

Como nos explica Domínguez Caparrós (1993, 28), la poesía se basa en una segmentación del discurso de índole rítmica, al margen de la segmentación lógico-sintáctica de la prosa. Es decir, el discurso poético se fragmenta por razones artísticas, para conseguir un ritmo artificioso del que carece la lengua coloquial. De esta manera, el discurso poético puede sentirse como un discurso entrecortado, que se aleja voluntariamente de la natural fluidez del lenguaje, sobre todo si esa segmentación rítmica se refuerza con un modelo de ejecución "rítmico", es decir, si los versos se escanden, bien sea en voz alta, bien sea mentalmente.

Ese discurso entrecortado de la poesía se acompaña de un tempo que puede percibirse como excesivamente rápido; además, sus límites pueden constreñir la materia poética. Esas pueden haber sido razones que impulsaron el nacimiento y desarrollo del versículo. Por otra parte, Juan Ramón Jiménez polemizó contra los modos incorrectos de lectura poética y sus ejemplos de ejecución responden a modelos de ejecución expresivos (no se marcan los finales de verso con pausa). Coherente con su concepción de ritmo universal, no distingue su prosa de su verso libre. Por eso podemos conjeturar que su empresa de presentar como prosa toda su producción en verso libre no fue un capricho incomprensible, como creyeron Gerardo Diego y Ricardo Gullón, sino que responde a intenciones rítmicas profundas. En el mismo sentido, Gimferrer, Talens, Siles y otros poetas novísimos innovaron el verso libre heredado y mediante los hiperversículos reanudaron los segmentos que la versificación tradicional impone al discurso poético; al mismo tiempo, reanudaron el diálogo con las proscritas vanguardias y las corrientes de modernismo anglosajón.

\section{CONCLUSIONES}

El versículo, el hiperversículo y la prosificación son fenómenos propios del desarrollo del verso libre de ritmo endecasilábico, y comparten su pretensión de superar los límites que impone la segmentación del discurso poético. El verso libre ha jugado un papel esencial en la evolución de la poesía contemporánea y, como nos advierten diversos críticos (Martínez Fernández, 1996; Blesa, 2001), su desarrollo se vincula con la crisis de la oralidad: "Se clausuraban aquí las imposiciones que la oralidad había imprimido sobre el discurso poético. En la era de la literatura escrita, tal requisito era ya superfluo, una excrecencia de otro universo literario (como el verso libre confirma)" (Blesa, 2001, 228).

Este parentesco de verso libre y prosa rítmica hizo que Juan Ramón Jiménez presentase como prosa la mayor parte de su poesía en su etapa americana. La indiferenciación de estas variedades poéticas en la conciencia de Juan Ramón Jiménez se acrecienta cuando observamos que lee sus poemas de acuerdo con un "modelo de ejecución" expresivo (Domínguez Caparrós, 1988b), es decir, guiado por la sintaxis y la semántica. Por tanto, para él, la lectura de un poema como Espacio en su versión en verso libre no se diferencia de la 
lectura de la versión en prosa. Juan Ramón Jiménez pretendía hacer concorde la tipografía con el modelo de ejecución que él adoptaba.

Sin embargo, a pesar de sus intentos de dar cuenta de la naturalidad del paso del verso libre a la prosa, Juan Ramón Jiménez no logró que sus lectores (entre los que se encontraban Gerardo Diego o Ricardo Gullón) asumieran que la base rítmica endecasilábica seguía funcionando tanto en la presentación en verso como en la presentación prosificada. Los largos versículos posteriores, pero sobre todo los hiperversículos de los novísimos vinieron a tender el puente necesario entre el verso libre inicial en la obra de Unamuno y Juan Ramón Jiménez y la prosa de ritmo endecasilábico, que encuentra un hito ineludible en el poema Espacio, pero que muestra su continuidad en las obras de Siles, Talens o Gamoneda.

Por otra parte, la preferencia del verso libre como modo de versificación y, en especial, el uso de versículos e hiperversículos deben entenderse como señales mediante las que el poeta manifiesta, en primera instancia, su intención rítmica (Domínguez Caparrós, 1988a, 23). Pero, además, como también Domínguez Caparrós señaló, las estructuras métricas tienen un evidente poder de creación de sentido (estético) y, por tanto, deben abordarse como fenómenos semióticos (1999, 93 y 98). En este sentido, los largos versículos e hiperversículos vinculan a la generación de los novísimos con las estéticas que inspiraron los poemarios surrealistas de la generación del 27 (Pasión de la tierra, Poeta en Nueva York, Un río, un amor, etc.), y muestran su voluntad de reintegrar la poesía española a la corriente predominante en la cultura europea y americana del siglo XX.

\section{NOTAS}

1 Véase Siles (1988), "Los novísimos: la tradición como ruptura, la ruptura como tradición", Hispanorama, 48, 122-130. Este artículo fue publicado posteriormente en Siles (2006), pp. 271284. Véase también Luna Borge $(1991,79)$.

2 Cicerón acuñó la denominación de poetae noui, y también la de neóteroi (es decir, juniores), en clara oposición a la poesía precedente.

3 Utilicé el concepto de "verso libre de ritmo endecasilábico", cuyo origen ignoro, en una publicación de 1984; más tarde he visto esta misma denominación en la monografía sobre el fragmentarismo de Martínez Fernández (1996) Dejo al margen el verso libre que hunde sus raíces últimas en Walt Whitman y la Biblia y que en nuestra lengua desarrolló Pablo Neruda.

4 Frente a la silva clásica, el modernismo introdujo dos modificaciones fundamentales, señaladas por Domínguez Caparrós (1993, 237): a) la rima asonante según el esquema del romance (silva arromanzada); y b) introducción de alejandrinos $(7+7)$, y otros versos impares (trisílabos, pentasílabos o eneasílabos).

5 Definición de versículo en su segunda acepción del Diccionario del español actual (Seco, Andrés, y Ramos, 1999): "línea de las que forman un poema en el que se prescinde del metro y de la rima, así como del ritmo propio de los versos".

6 Me refiero naturalmente a Aleixandre y Cernuda, y a García Lorca cuyo asesinato cortó la obra poética española más impresionante del siglo XX. 
7 La denominación de "poema en bloque" procede de Martínez García, como anota Martínez Fernández (1996, 76).

8 Este miembro podría entenderse como un heptasílabo; esa solución implica que debe pronunciarse la conjunción y como tónica y que no se realiza la sinalefa. Sin embargo, este poema se presenta como "bloque" en prosa y, por tanto, no hay ninguna señal tipográfica de final de verso o hemistiquio. La lectura debe seguir un "modelo de ejecución" expresivo (Domínguez Caparrós, 1993, 41-43), es decir, guiado por la sintaxis y la semántica. En esas condiciones, la conjunción no se pronuncia como tónica y la sinalefa es casi inevitable. Esto permitiría la escansión en.la.le.jí.ay, que nos llevaría a considerarlo como pentasílabo. Mediante comunicación personal, el poeta Antonio Carvajal me ofrece el siguiente ejemplo, que haría plausible ese análisis: "niña blanca, si has nacido en" (Juan Ramón Jiménez, Las hojas verdes, "Otras baladas"); se trata de un octosílabo con sinalefa de la preposición átona en. También mediante comunicación personal, Dionisio Pérez aporta este pasaje: "su mano, que se vestían / de seda rosa y... / Silencio" (Juan Ramón Jiménez, Pastorales X), donde es necesaria la sinalefa ro.say para que se respete el ritmo octosilábico del poema.

9 Mido los segmentos rítmicos siguiendo la tradición catalana, el decasílabo corresponde al endecasílabo italiano y castellano, el hexasílabo al heptasílabo, etc.

\section{REFERENCIAS BIBLIOGRÁFICAS}

ALEIXANDRE, V. 1977. Obras completas. Madrid: Aguilar.

BIELER, L. 1982. Historia de la literatura romana. Madrid: Gredos.

BLESA, T. 1995. Leopoldo María Panero, el último poeta. Madrid: Valdemar.

BLESA, T. 2001. "Prescripciones", Signa: Revista de la Asociación Española de Semiótica, 10, 219-232.

CASTELLET, J. M. 1970. Nueve novísimos poetas españoles. Barcelona: Seix Barral.

CRISTÓBAL, V. 2000. "Mitología clásica en la literatura española: consideraciones generales y bibliografía”, Cuadernos de Filología Clásica. Estudios latinos, 18, 29-76.

DOMÍNGUEZ CAPARRÓS, J. 1988a. Métrica y poética. Bases para la fundamentación de la métrica en la teoría literaria moderna. Madrid: UNED.

DOMÍNGUEZ CAPARRÓS, J. 1988b. "Los conceptos de modelo y ejemplo de verso, y de ejecución", Epos, 4, 241-258.

DOMÍNGUEZ CAPARRÓS, J. 1992. "La métrica y los estudios literarios”, Epos, 8, 245-260.

DOMÍNGUEZ CAPARRÓS, J. 1993. Métrica española. Madrid: Síntesis.

DOMÍNGUEZ CAPARRÓS, J. 1999. Estudios de métrica. Madrid: UNED.

GAMONEDA, A. 1986. Lápidas. Madrid: Trieste.

GARCÍA POSADA, M. (ed.). 1996. Poesía española 10. La nueva poesía (1975-1992). Barcelona: Crítica.

GIMFERRER, P. 1979. Poemas. 1963-1969. Madrid: Visor.

GIULANI, A. 1961. I Novissimi. Poesie per gli anni '6o. Milán: Ruscolini-Paolazzi.

JIMÉNEZ, J. R. 1970. Tercera antolojía poética. Madrid: Biblioteca Nueva.

JIMÉNEZ, J. R. 1999. Lírica de una Atlántida, en Alegre Heitzmann, A. (ed.), Barcelona: Galaxia Gutenberg - Círculo de Lectores.

LUNA BORGE, J. 1992. La generación poética del 7o. Sevilla: Qüásyeditorial. 
MÁRQUEZ, M. Á. 200o. "El versículo en el verso libre de ritmo endecasilábico”, Bulletin of Hispanic Studies, 77, 217-234.

MÁRQUEZ, M. Á. 2001. "La rima en la poesía última de Vicente Aleixandre”, Hispanic Review, 69(3), 337-353.

MÁRQUEZ, M. Á. 2003. "Verso y prosa en la etapa americana de Juan Ramón Jiménez", Rhythmica, 1, 149-181.

MARTÍNEZ FERNÁNDEZ, J. E. 1996. El fragmentarismo poético contemporáneo. León: Secretariado de Publicaciones, Universidad de León.

MORENO JURADO, J. A. 1990. Nugae. Antología poética (1973-199o). Sevilla: Secretariado de Publicaciones, Universidad de Sevilla.

OLIVIO JIMÉNEZ, J. 1998. Diez años decisivos en la poesía española contemporánea, 196o1970. Madrid: Rialp.

PAZ GAGO, J. M. 2001. “¿Una métrica de nueva planta? Métrica y teoría de la literatura”, Signa: Revista de la Asociación Española de Semiótica, 10, 339-362.

SIEBENMANN, G. 1973. Los estilos poéticos en España desde 190o. Madrid: Gredos.

SILES, J. 1992. Poesía 1969-199o. Madrid: Visor.

SILES, J. 2006. Estados de conciencia. Ensayos sobre poesía española contemporánea. Madrid: Abada.

TALENS, J. 1986. Purgatorio. Versión castellana de A. Cabanilles. Madrid: Hiperión.

\section{NOTA SOBRE EL AUTOR}

Miguel Ángel Márquez Guerrero es Catedrático de Teoría de la Literatura en la Universidad de Huelva, España. 